\title{
Seismic response of waste storage tanks
}

\author{
Kamila Kotrasova ${ }^{1, a}$ and Eva Kormanikova ${ }^{1}$ \\ ${ }^{1}$ Department of Structural Mechanics, Institute of Structural Engineering, The Technical University of Kosice, Faculty of Civil Engineering, \\ Vysokoskolska 4, 04200 Kosice, Slovak Republic
}

\begin{abstract}
Ground- supported cylindrical tanks are used to store a variety of liquids. This paper provides the theoretical background for takes into account impulsive and convective (sloshing) actions of the fluid in concrete containers fixed to rigid foundations; it has been adopted in Eurocode 8. Seismic responses - base shears, the bending and overturning moments - are calculated by using the response spectra of the earthquake in Loma Prieta, California. As the examples is analyzed the ground supported cylindrical concrete tanks, where for constant fluid filling $H, R$ are depended from parameters tank slenderness ratio $\gamma=H / R$
\end{abstract}

\section{Introduction}

Ground-supported cylindrical tanks are strategically very important structures, since they have vital uses in industries, nuclear power plants and are connected to public life. Liquid storage tanks are used to store a variety of liquids, e.g. water for drinking and fire fighting, petroleum, oil, liquefied natural gas, chemical fluids, chemical and radioactive wastes. Seismic safely of liquid tanks is of considerable importance [1-8]. Water storage tanks should remain functional in the post earthquake period to ensure potable water supply to earthquake-affected regions and to cater the need for fighting demand. Industrial liquid tanks containing highly toxic and inflammable liquids and these tanks should not lose their contents during the earthquake. Satisfactory performance of tanks during strong ground shaking is crucial for there modern facilities. The seismic behavior of liquid storage tanks is highly complex problem due to liquid-structure interaction. Tanks that were inadequately designed or detailed have suffered extensive damage during past earthquakes [9-12].

\section{Cylindrical tank and behaviour}

Among the different structural forms of liquid containers, the ground supported upright cylindrical tank is the most commonly used type because it is very efficient in withstanding the hydrostatic load caused by the liquid content.

A typical cylindrical tank is shown in Figure 1. It essentially consists of a base plate rested on the ground and a vertically erected shell wall. Optionally, there may be a floating or fixed roof to protect the liquid content from the outside air, column(s) inside the tank to support

\footnotetext{
a Corresponding author: kamila.kotrasova@tuke.sk
}

the roof, ring girders to enhance the stiffness of the wall and to improve its stability, and anchorage along the border of the base plate to prevent uplift. For a broad tank with its diameter, and therefore the tank is generally left unanchored.

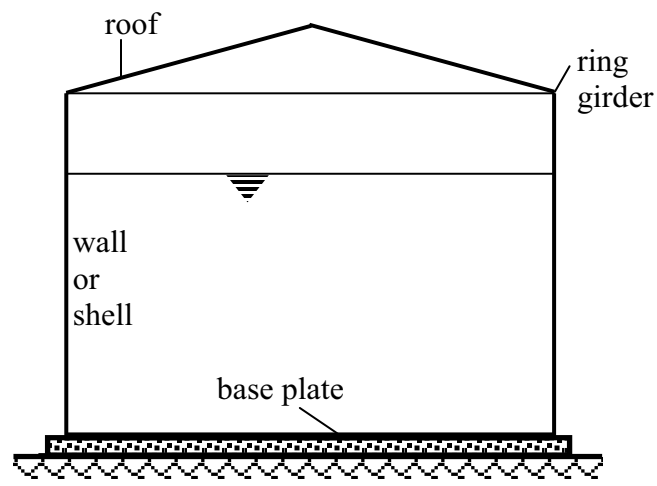

Figure 1. Typical cylindrical tank

Under the static condition, a cylindrical liquid storage tank is subjected to axisymmetric hydrostatic pressure caused by the liquid content acting radially outwards on the vertical tank shell wall. Hoop tensile force is developed in tank shell wall to withstand this pressure. In static design of a cylindrical tank, the required shell thickness of the shell wall is determined by the magnitude of this hoop tensile force. Under the static condition the base plate and the other parts of the tank structure bear no significant load and thus can be designed just to comply with the minimum structural requirements.

When a liquid storage tank is subjected to seismic load, vibration motion of the liquid content is developed due to the ground excitation acting on it via the tank 
structure. The first one, defined as the "impulsive mode", consists of the liquid particles moving in unison with the motion of the tank structure. The second one, defined as the "convective mode" or usually called "sloshing", consists of the liquid particles near the free surface oscillating vertically. The resultant load effect of the liquid motion is generally represented by a total base shear and an overturning moment. In response to the hydrodynamic load, axial compressive and tensile stresses as well as additional hoop stress are developed in the tank shell wall. These stresses are asymmetric and much greater than that due to the hydrostatic pressure under the static condition. For an unanchored tank subjected to a sufficiently large resultant overturning moment, a portion of the base plate will separate from the support foundation. Accompanying with the base plate uplift, extensive deformations with significant out-of round distortion occur in the tank shell wall. The phenomenon is called the "uplift mechanism". The "uplift mechanism" is highly nonlinear to the applied load. The significant deformation and violet motion of the tank structure in turn greatly affect the liquid motion, and thud the hydrodynamic load.

Based on field observations, the typical failure modes of liquid storage tanks can be summarized as follows [2]:

- failure of the base plate,

- buckling of the tank shell wall,

- rupture of the tank shell wall at anchorage,

- failure of anchorage,

- failure of roof,

- total collapse,

- failure off partial settlement of foundation,

- sliding walk-off of foundation due to rocking,

- damages to piping connections or other equipments.

For unanchored liquid storage tanks, buckling of the tank shell wall is the most common type of structure damage due to the narrow concentration and high magnitude of the compressive force developed in the tank shell wall when the tank base plate is partially uplifted from the ground support during an earthquake. Failure of the tank roof, due to the impact from the intense liquid sloshing and damage to piping connection, due to the large displacement of the tank structure during dynamic response, are also frequently reported for unanchored liquid storage tanks.

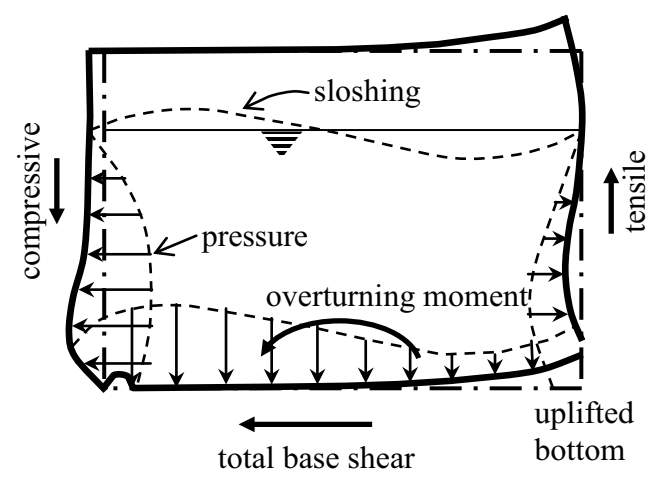

Figure 2. Hydrodynamic pressure and resultants
Figure 2 illustrates the typical hydrodynamic effect and resultants.

\section{Mechanical model}

The dynamic analysis of a liquid - filled tank may be carried out using the concept of generalized single degree - of freedom (SDOF) systems representing the impulsive and convective modes of vibration of the tank liquid system as shown in Figure 3. For practical applications, only the first convective modes of vibration need to be considered in the analysis, mechanical model. The impulsive mass of liquid $m_{i}$ is rigidly attached to tank wall at height $h_{i}$. Similarly convective mass $m_{c n}$ is attached to the tank wall at height $h_{c n}$ by a spring of stiffness $k_{c n}$. The mass, height and natural period of each SDOF system are obtained by the methods described in [13].

\section{Seismic analysis of liquid filled tanks}

The seismic analysis of a liquid-filled tank may by carried out using the concept of generalized singledegree-of-freedom systems representing the impulsive and convective modes of vibration of tank-liquid system. The problem of fluid-structure interaction is very important in case of high tanks. The motion of fluid in the tank is possible to define using the simple quasistatic model, in which the inertial forces are defined by hydrostatic and hydrodynamic pressure on the tank wall.

\subsection{Formatting the text}

The seismic loads acting on wall and bottom of cylindrical tanks (Figure 2) can be divided into the following components:

- The rigid impulsive component, caused by the inertia of the liquid, if the rigid tank moves together with the foundation,

- the convective load component; the fluid vibration in the rigid tank (sloshing),

- the impulsive flexible tank shell (e.g. steel tanks) with the liquid.

The motion of the fluid contained in a rigid cylinder may by expressed as the sum of two separate contributions, called "rigid impulsive" and "convective", respectively. The "rigid impulsive" component satisfies exactly the boundary conditions at the walls and the bottom of the tank, but gives (incorrectly, due to the presence of the waves in the dynamic response) zero pressure at the original position of the free surface of the fluid in the static situation. The "convective" term does not alter those boundary conditions that are already satisfied, while fulfilling the correct equilibrium condition at the free surface. Use is made of a cylindrical coordinate system: $r, z, \theta$, with origin at the centre of the tank bottom and the radius are denoted by $H$ and $R$, respectively, $\rho$ is the mass density of the fluid, while $\xi=r / R$ is dimensionless radius and $\zeta=z / H$ is nondimensional coordinate. 


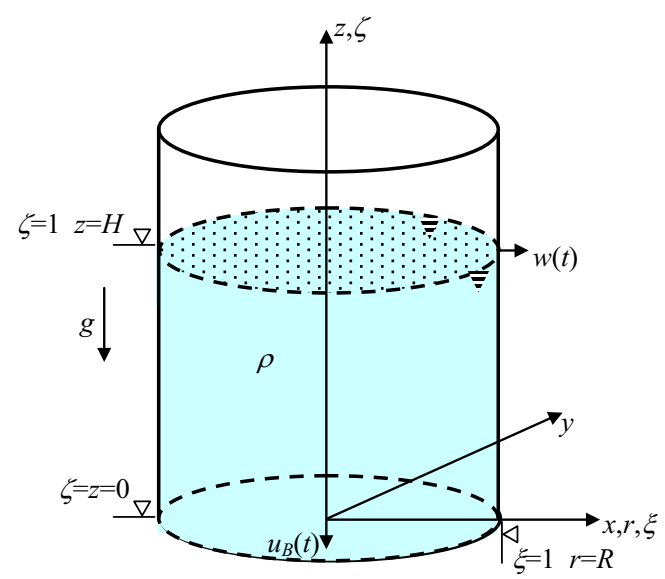

Figure 3. Cylindrical tank
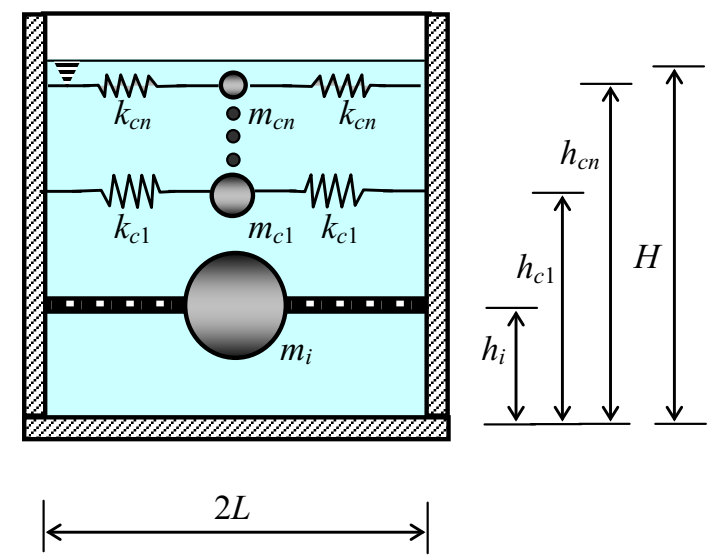

Figure 4. Liquid-filled tank modeled by generalized single degree of freedom systems

\subsection{Rigid impulsive component}

The seismic loads acting on wall and bottom of cylindrical tanks (Figure 2) can be divided into the following components:

The spatial-temporal variation of the "rigid impulsive" pressure is given by the expression

$$
p_{i}(\xi, \zeta, \theta, t)=C_{i}(\xi, \zeta) \rho H \cos \theta A_{g}(t),
$$

where

$$
C_{i}(\xi, \zeta)=2 \sum_{n=0}^{\infty} \frac{(-1)^{n}}{I_{1}^{\prime}\left(v_{n} / \gamma\right) v_{n}^{2}} \cos \left(v_{n} \zeta\right) I_{1}\left(\frac{v_{n}}{\gamma} \xi\right),
$$

$v_{n}=\pi \frac{2 n+1}{2}$ and $\gamma=H / R, I_{1}($.$) is the modified Bessel$ function of order 1 and $I_{1}^{\prime}(\cdot)$ is derivate can be expressed in terms of modified Bessel function of order 0 and 1 $I_{1}^{\prime}(x)=\frac{d I_{1}(x)}{d x}=I_{0}(x)-\frac{I_{1}(x)}{x}$. The function $C_{i}$ gives the distribution along the height of $p_{i} . \quad \theta$ is angle of circumference, $\gamma=H / R$ is slenderness, $A_{g}(t)$ is the ground horizontal acceleration time-history in free-field with peak value denoted by $a_{g}$ as a result of an equivalent single-degree-of-freedom system with a impulsive period $T_{i}$.

Impulsive base shear is at the base of the wall is given

$$
Q_{i}(t)=m_{i} A_{g}(t)
$$

$m_{i}$ is termed impulsive mass, denoted the mass of the contained fluid which moves together with the walls and is given by the expression:

$$
m_{i}=m 2 \gamma \sum_{n=0}^{\infty} \frac{I_{1}\left(v_{n} / \gamma\right)}{v_{n}^{3} I_{1}^{\prime}\left(v_{n} / \gamma\right)},
$$

where $m=\rho \pi R^{2} H$ is total contained mass of the fluid.

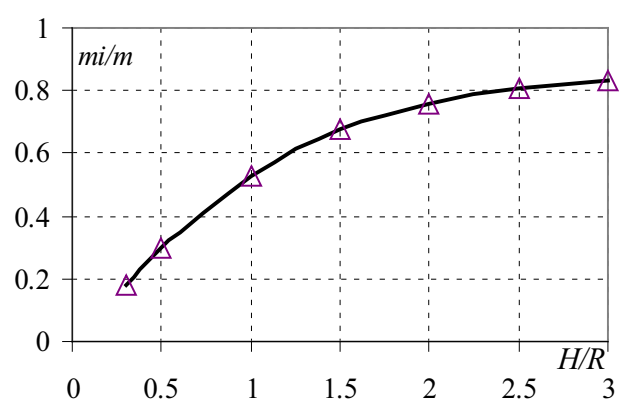

Figure 5. Ratios $m_{i} / m$ as function of the parameter tank slenderness

The total moment with respect to an axis orthogonal to the direction of the seismic action motion, $M_{i}^{*}$, immediately bellow the tank bottom includes the contributions of the pressures on the walls from expression (1) and of those on the tank bottom. The total moment $M_{i}$ immediately above the tank bottom includes only the contributions of the pressures on the walls.

Impulsive base moment immediately below the tank bottom:

$$
M_{i}^{*}=m_{i} h_{i}^{*} A_{g}(t)
$$

where

$$
h_{i}^{*}=H \frac{\frac{1}{2}+2 \gamma \sum_{n=0}^{\infty} \frac{v_{n}+2(-1)^{n+1} I_{1}\left(v_{n} / \gamma\right)}{v_{n}^{4} I_{1}^{\prime}\left(v_{n} / \gamma\right)}}{2 \gamma \sum_{n=0}^{\infty} \frac{I_{1}\left(v_{n} / \gamma\right)}{v_{n}^{3} I_{1}^{\prime}\left(v_{n} / \gamma\right)}} .
$$

Impulsive base moment immediately above the tank bottom:

$$
M_{i}=m_{i} h_{i} A_{g}(t)
$$

where

$$
h_{i}=H \frac{\sum_{n=0}^{\infty} \frac{(-1)^{n} I_{1}\left(v_{n} / \gamma\right)}{v_{n}^{4} I_{1}^{\prime}\left(v_{n} / \gamma\right)}\left(v_{n}(-1)^{n}-1\right)}{\sum_{n=0}^{\infty} \frac{I_{1}\left(v_{n} / \gamma\right)}{v_{n}^{3} I_{1}^{\prime}\left(v_{n} / \gamma\right)}} .
$$




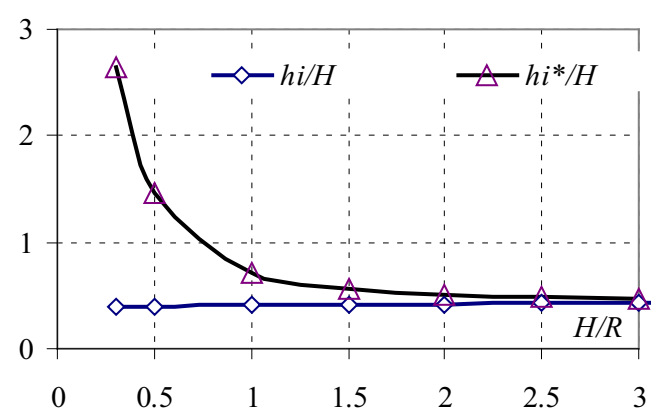

Figure 6. Ratios $h_{i} / H$ and $h_{i}{ }^{*} / H$ as functions of the parameter tank slenderness

\subsection{Convective component}

The spatial-temporal variation of the "convective" pressure component is given by the expression

$$
p_{c}(\xi, \zeta, \theta, t)=\rho \sum_{n=1}^{\infty} \psi_{n} \cos \left(v_{n} \gamma \zeta\right) J_{1}\left(v_{n} \xi\right) \cos \theta A_{c n}(t),
$$

where

$$
\psi_{n}=\frac{2 R}{\left(\lambda_{n}^{2}-1\right) J_{1}\left(\lambda_{n}\right) \cosh \left(\lambda_{n} \gamma\right)},
$$

$J_{1}$ is Bessel function of the first order, $\lambda_{n}$ are the roots of the first-order Bessel function of the first kind $\left(\lambda_{1}=1.8412 ; \lambda_{2}=5.3314 ; \lambda_{3}=8.5363, \lambda_{4}=11.71, \lambda_{5}=14.66\right.$ and $\left.\lambda_{5+i}=\lambda_{5}+5 i(i=1,2, \ldots)\right)$. $A_{c n}(t)$ is acceleration timehistory of the response of a single degree of freedom oscillator having a circular frequency $\omega_{c n}$ was given by

$$
\omega_{c n}=\sqrt{\frac{g \lambda_{n} \tanh \left(\lambda_{n} \gamma\right)}{R}}
$$

so

$$
T_{c n}=\frac{2 \pi}{\sqrt{\frac{g \lambda_{n} \tanh \left(\lambda_{n} \gamma\right)}{R}}}
$$

and a damping ratio appropriate for the sloshing of the fluid.

Only the first oscillating, or sloshing, mode and frequency of the oscillating liquid $(n=1)$ needs to be considered in expression for design purposes.

$$
\omega_{c 1}=4,2 / \sqrt{R}
$$

which, for the usual values of $R$ yields periods of oscillation of the order of few seconds.

Convective base shear is given

$$
Q_{c}(t)=\sum_{n=1}^{\infty} m_{c n} A_{c n}(t)
$$

where

$$
m_{c n}=m \frac{2 \tanh \left(\lambda_{n} \gamma\right)}{\lambda_{n} \gamma\left(\lambda_{n}^{2}-1\right)}
$$

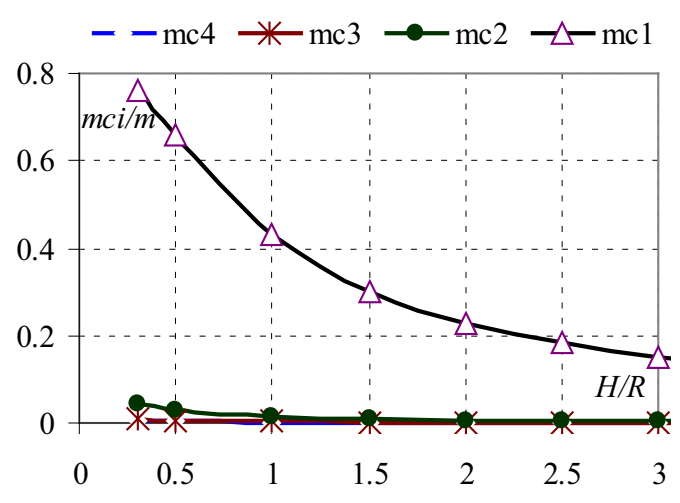

Figure 7. Ratios $m_{c i} / m$ as function of the parameter tank slenderness for $i=1,2,3$ and 4

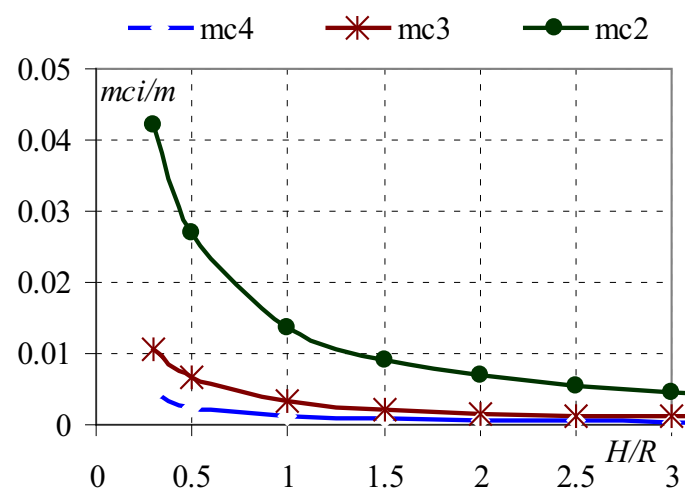

Figure 8. Ratios $m_{c i} / m$ as function of the parameter tank slenderness for $i=2,3$ and 4

Only the first oscillating, or sloshing, mode and frequency of the oscillating liquid $(n=1)$ needs to be considered in expression for design purposes.

$$
\omega_{c 1}=4,2 / \sqrt{R}
$$

which, for the usual values of $R$ yields periods of oscillation of the order of few seconds.

Convective base shear is given

$$
Q_{c}(t)=\sum_{n=1}^{\infty} m_{c n} A_{c n}(t)
$$

where

$$
m_{c n}=m \frac{2 \tanh \left(\lambda_{n} \gamma\right)}{\lambda_{n} \gamma\left(\lambda_{n}^{2}-1\right)}
$$

Moment immediately below the bottom plate of the tank:

$$
M_{c}^{\prime}(t)=\sum_{n=1}^{\infty}\left(m_{c n} A_{c n}(t)\right) h_{c n}^{*}=\sum_{n=1}^{\infty} Q_{c n}(t) h_{c n}^{*}
$$

where 


$$
h_{c n}^{*}=H\left(1+\frac{2-\cosh \left(\lambda_{n} \gamma\right)}{\lambda_{n} \gamma \sin \left(\lambda_{n} \gamma\right)}\right)
$$

Moment in tank wall immediately above the bottom plate

$$
M_{c}(t)=\sum_{n=1}^{\infty}\left(m_{c n} A_{c n}(t)\right) h_{c n}=\sum_{n=1}^{\infty} Q_{c n}(t) h_{c n}
$$

where

$$
h_{c n}=H\left(1+\frac{1-\cosh \left(\lambda_{n} \gamma\right)}{\lambda_{n} \gamma \sin \left(\lambda_{n} \gamma\right)}\right)
$$

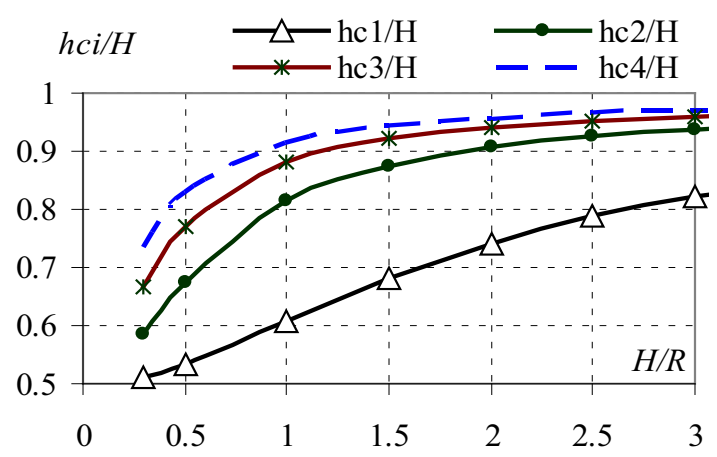

Figure 9. Ratios $h_{c i} / H$ as functions of the parameter tank slenderness

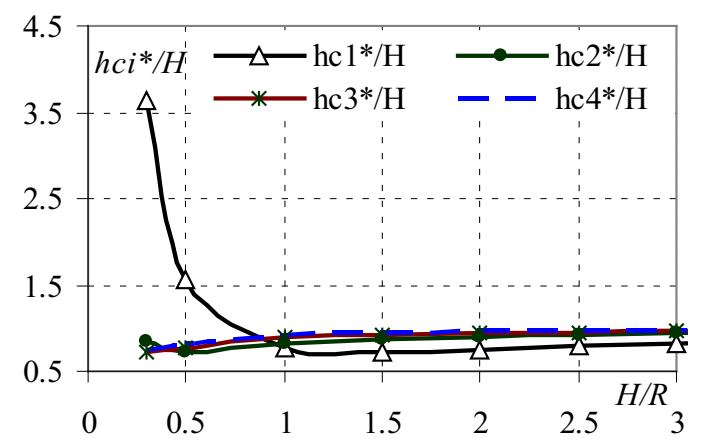

Figure 10. Ratios $h_{c i}{ }^{*} / H$ as functions of the parameter tank slenderness

The convective component of the response may be obtained from that of oscillators having masses $m_{c n}$, attached to the rigid tank through springs having stiffness $k_{n}=\omega_{n}^{2} m_{c n}$. The tank is subjected to the ground acceleration time-history $A_{g}(t)$ and the masses respond with accelerations $A_{c n}(t) \cdot h_{c n}^{*}$ or $h_{c n}$ is the level where the oscillator needs to be applied in order to give the correct value of $M_{c n}^{*}$ or $M_{c n}$, respectively.

\subsection{Flexible component}

It is normally unconservative to consider the tank as rigid (especially for steel tanks). In flexible tanks the fluid pressure is usually expressed as the sum of tree contributions, referred to as: "rigid impulsive", "sloshing" and "flexible". The third satisfied the condition that the radial velocity of the fluid along the wall equals the deformation velocity of the tank wall, as well as the conditions of zero vertical velocity at the tank bottom and zero pressure at the free surface of the fluid. The dynamic coupling between the sloshing and the flexible components is very weak, due to the large differences between the frequencies of the sloshing motion and of the deformation of the wall, which allows determining the third component independently of the others.

The radial distribution of the flexible impulsive pressure on the tank bottom is qualitatively the same as for the rigid impulsive pressure. Assuming the modes as known, the flexible pressure distribution on the walls has the form

$$
p_{f}(\zeta, \theta, t)=\rho H \psi \cos \theta \sum_{n=1}^{\infty} \cos \left(v_{n} \zeta\right) A_{f n}(t)
$$

For a horizontal earthquake ground motion, the response of various SDOF systems may be calculated independently and then combined to give the base shear and overturning moment. The most tanks have the parameter tank slendernes $\gamma$, whereby $0,3<\gamma<3$. The parameter tank slendernes is given by relation $\gamma=H / L$, where $H$ is the filling height of fluid in the tank and $2 L$ is inside width of tank.

Values mi, $h_{i}, h_{i}{ }^{*}, m_{c n}, h_{c n}$, and $h_{c n}{ }^{*}$ for rigid vertical circular tanks on ground, fixed to the foundation in Eurocode 8 - 4 [13] are shown in Figure 7 - 10.

\section{Numerical example and results}

In this study is analyzed fluids filling of ground supported cylindrical rigid tank. The characteristics of fluid filling for $H=2 \mathrm{~m}$, where $R$ - inner radiuses of cylindrical tanks are depended from tank slenderness ratios $\gamma=H / R$.

For tank slenderness ratio $\gamma=0.3$, the inner radius of tank $R$ is given $6.667 \mathrm{~m}$,

$$
\begin{aligned}
& \text { - for } \gamma=0.5 \Rightarrow R \text { is } 4 \mathrm{~m}, \\
& \text { - for } \gamma=0.7 \Rightarrow R=2.857 \mathrm{~m}, \\
& \text { - for } \gamma=1 \Rightarrow R=2 \mathrm{~m}, \\
& \text { - for } \gamma=2 \Rightarrow R=1 \mathrm{~m}, \\
& \text { - } \text { and for } \gamma=3, R \text { is given } 0.667 \mathrm{~m} \text {. }
\end{aligned}
$$

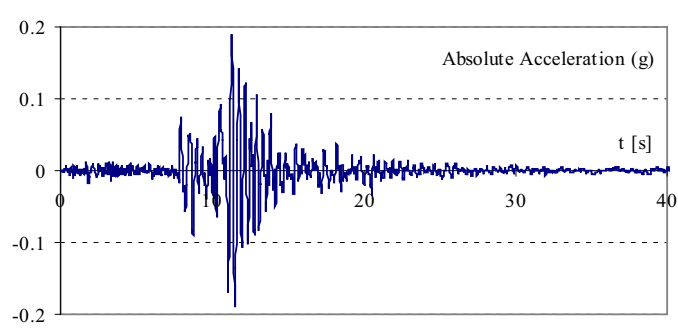

Figure 11. Accelerogram Loma Prieta, California 
The material characteristics of fluid filling $\left(\mathrm{H}_{2} \mathrm{O}\right)$ is density $\rho_{w}=1000 \mathrm{~kg} / \mathrm{m}^{3}$. As the excitation input we consider horizontal earthquake load given by the accelerogram of the earthquake in Loma Prieta, California (18.10.1989), Figure 11. Seismic responses of tanks are calculated by using the response spectrums for the Loma Prieta accelerogram, California, Figure 12.

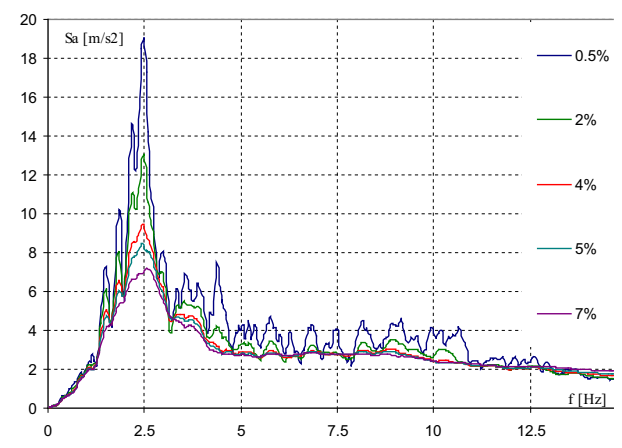

Figure 12. Response spectrums for the Loma Prieta accelerogram from Figure 11

The elastic response spectrums of the Loma Prieta accelerogram (Figure 11) were used for simulation of earthquake. The impulsive spectral accelerations are obtained from a 5\% damped elastic response spectrum (for concrete tanks) and the convective spectral accelerations are obtained from a $0.5 \%$ damped elastic response spectrum.

Table1. comparison of the total base shears, the bending and overturning moments of fluid as functions of the tank slenderness

\begin{tabular}{|c|c|c|c|c|}
\cline { 2 - 5 } \multicolumn{1}{c|}{} & $\begin{array}{c}\boldsymbol{D} \\
{[\mathrm{m}]}\end{array}$ & $\begin{array}{c}\boldsymbol{V} \\
{[\mathrm{kN}]}\end{array}$ & $\begin{array}{c}\boldsymbol{M} \\
{[\mathrm{kNm}]}\end{array}$ & $\begin{array}{c}\boldsymbol{M}^{*} \\
{[\mathrm{kNm}]}\end{array}$ \\
\hline $\boldsymbol{\gamma}=\mathbf{0 . 3}$ & 13.333 & 7643.55 & 7780.72 & 51013.9 \\
\hline $\boldsymbol{\gamma}=\mathbf{0 . 5}$ & 8 & 7751.87 & 8284.86 & 23463.3 \\
\hline $\boldsymbol{\gamma}=\mathbf{0 . 7}$ & 5.714 & 2153.03 & 2349.75 & 4352.12 \\
\hline $\boldsymbol{\gamma}=\mathbf{1}$ & 4 & 1744.58 & 2065.91 & 2711.89 \\
\hline $\boldsymbol{\gamma}=\mathbf{2}$ & 2 & 179.51 & 224.97 & 235.39 \\
\hline $\boldsymbol{\gamma}=\mathbf{3}$ & 1.333 & 46.86 & 50.42 & 51.79 \\
\hline
\end{tabular}

Comparison of the total base shears $V$, the bending moments $M$ and overturning moments $M^{*}$ of fluid as functions of the tank slenderness ratios for diameters $D=$ $2 R$ are shown in Table 1.

\section{Conclusions}

The ground supported cylindrical tank was excited by ground motion of Loma Prieta in California. Basic responses of the interest were: the total base shears, the bending and overturning moments of fluid as functions of the tank parameter slenderness ratio.

\section{Acknowledgment}

This work was supported by the Scientific Grant Agency of the Ministry of Education of Slovak Republic and the Slovak Academy of Sciences under Project VEGA 1/0477/15.

\section{References}

[1] A. Di Carluccio, G. Manfredi, I. Iervolino, G. Fabbrocino, Fragility analysis of liquid storage steel tanks in seismic areas. Proceedings of ISEC-4 Innovations in Structural Engineering and Construction (2008) 2, p. 1049-1055.

[2] S. Dorafshan, F. Behnamfar, A. Khamesipour. M. Motosaka, Condensed hyperelements method of nonvertical consistent boundaries for wave propagation analysis in irregular media. Earthquake engineering and engineering vibration (2013) 12, p. 547-559.

[3] G. Fabbrocino, I. Iervolino, I. Orlando, E. Salzano, Quantitative risk analysis of oil storage facilities in seismic areas (2005) 123 (1-3), Journal of Hazardous Materials, pp. 61-69.

[4] N. Jendzelovsky, N., L. Balaz, Numerical Modeling of Cylindrical Tank and Compare with Experiment. In: Applied Mechanics and Materials (2013) 617, ISSN 1660-9336. p. 148-151.

[5] K. Kralik, J. Kralik jr., Probability assessment of analysis of high-rise buildings seismic resistance, Advanced Materials Research (2013) 712-715, p. 929-936.

[6] M. Krejsa, P. Janas, V. Krejsa, Software application of the DOProC method In: International Journal of Mathematics and Computers in Simulation (2014) 8, ISSN 1998-0159, p. 121-126.

[7] P. K. Malhotra, T. Wenk, M., Wieland, Simple procedure for seismic analysis of liquid-Storage tanks. Structural Engineering International, (2000) 3, s. 197-201.

[8] J. Melcer, Experimental testing of a bridge. Applied Mechanics and Materials (2014) 486, pp. 333-340.

[9] J., Michel, M. Mihalikova, Degradation of pipes properties in creep conditions. In: Acta Metallurgica Slovaca (2000) 2, p. 108-115. ISSN 1335-1532.

[10] O. Sucharda, J. Brozovsky, Bearing capacity analysis of reinforced concrete beams, International Journal of Mechanics (2013) 7, Issue 3, p. 192-200.

[11]B. Taraba, Z Michalec, V. Michalcova, T. Blejchar, M Bojko, M Kozubkova. CFD simulations of the effect of wind on the spontaneous heating of coal stockpiles. Fuel (2014) 118, ISSN 0016-2361, p. 107-112.

[12] M. Zmindak, I. Grajciar, Simulation of the aquaplane problem. Computers and Structures (1977) 64, Issue 5-6, p. 1155-1164.

[13] Eurocode 8 - Design of structure for earthquake resistance - Part. 4: Silos, tanks and pipelines. Januar 2006. 